\title{
BMJ Open Changes in left ventricular relaxation after azelnidipine treatment in hypertensive patients with diabetes: subanalysis of a prospective single-arm multicentre study
}

\author{
Katsuomi Iwakura, ${ }^{1}$ Hiroshi Ito, ${ }^{2}$ Katsuhisa Ishii, ${ }^{3}$ Motoo Date, ${ }^{1}$ Fumiaki Nakamura, ${ }^{4}$ \\ Toshihiko Nagano, ${ }^{5}$ Shin Takiuchi, ${ }^{6}$ for the Clinical impact of Azelnidipine on Left \\ VentricuLar diastolic function and OutComes in patients with hypertension \\ (CALVLOC) trial investigators
}

To cite: Iwakura $\mathrm{K}$, Ito $\mathrm{H}$, Ishii $\mathrm{K}$, et al. Changes in left ventricular relaxation after azelnidipine treatment in hypertensive patients with diabetes: subanalysis of a prospective single-arm multicentre study. BMJ Open 2014:4:e006136.

doi:10.1136/bmjopen-2014006136

- Prepublication history for this paper is available online. To view these files please visit the journal online (http://dx.doi.org/10.1136/ bmjopen-2014-006136).

Received 18 July 2014 Revised 14 August 2014 Accepted 21 August 2014

CrossMark

For numbered affiliations see end of article.

Correspondence to Dr Katsuomi Iwakura; iwakura@mac.com

\section{ABSTRACT}

Objectives: We previously demonstrated that a calcium channel blocker, azelnidipine, improves left ventricular relaxation in patients with hypertension and diastolic dysfunction in a multicentre, Clinical impact of Azelnidipine on Left VentricuLar diastolic function and OutComes in patients with hypertension (CALVLOC) trial. The objectives of the present subanalysis were to investigate the differences in diastolic function in hypertensive patients with and without diabetes, and the efficacy of azelnidipine on diastolic function among them.

Design: Subanalysis of a prospective single-arm multicentre study.

Participants: 228 hypertensive patients with normal ejection fraction and impaired left ventricular relaxation (septal $\mathrm{e}^{\prime}$ velocity $<8 \mathrm{~cm} / \mathrm{s}$ on echocardiography) enrolled for CALVLOC trial. They were divided into two groups based on presence or absence of diabetes.

Interventions: Administration of $16 \mathrm{mg}$ of azelnidipine for 8 months (range 6-10 months).

Main outcome measures: Septal $\mathrm{e}^{\prime}$ velocity before and at the end of the study.

Results: Whereas patients with diabetes $(n=53$, $23.2 \%$ ) had lower systolic blood pressure (BP) than patients without diabetes $(155 \pm 17$ vs $161 \pm 16 \mathrm{~mm} \mathrm{Hg}$, $p=0.03$ ), they had lower $e^{\prime}$ velocity ( $5.7 \pm 1.5$ vs 6.1 $\pm 1.4 \mathrm{~cm} / \mathrm{s}, p=0.04$ ) at baseline. Azelnidipine decreased $\mathrm{BP}$ and heart rate, and increased $\mathrm{e}^{\prime}$ velocity similarly in patients with diabetes $(5.7 \pm 1.5$ to $6.3 \pm 1.5 \mathrm{~cm} / \mathrm{s}$, $\mathrm{p}=0.0003)$ and without diabetes $(6.1 \pm 1.4$ to 6.9 $\pm 1.4 \mathrm{~cm} / \mathrm{s}, p<0.0001)$. Increase in $\mathrm{e}^{\prime}$ velocity was not influenced by presence of diabetes, and patients with diabetes still had lower $\mathrm{e}^{\prime}$ velocity after treatment $(p=0.006)$. There was a significant correlation between increase in $\mathrm{e}^{\prime}$ velocity and decrease in systolic $\mathrm{BP}$ $(R=0.25, p=0.0001)$, which was not influenced by diabetes.

Conclusions: Comorbid diabetes could impair left ventricular relaxation independently in patients with

\section{Strengths and limitations of this study}

- Based on a prospective, multicentre trial, the difference in left ventricular (LV) relaxation in hypertensive patients with or without diabetes was investigated.

- Azelnidipine, a unique calcium channel blocker that lowers blood pressure without increasing heart rate, was used as an intervention to improve LV relaxation.

- LV relaxation was more impaired in hypertensive patients with diabetes than in those without diabetes, and azelnidipine improved LV relaxation in both groups to the same degree.

- The persistence of diastolic dysfunction in diabetic patients after azelnidipine treatment implied that hypertension and diabetes might impair diastolic function through different mechanisms.

- This was a subanalysis of a one-arm, open-label study including only 228 patients and, therefore, the results might be inconclusive as to the impact of diabetes on diastolic function.

hypertension, which might not be improved solely by BP lowering.

Hypertension and diabetes are two major risk factors for heart failure with preserved ejection fraction, and both of them are highly associated with left ventricular (LV) diastolic dysfunction. ${ }^{1-3}$ These two diseases frequently coexist and often share comorbidities and conditions that can affect LV function, such as obesity and LV hypertrophy. Therefore, it is not easy to clarify how hypertension and diabetes are interacted in the development of LV diastolic dysfunction. 
Appropriate blood pressure (BP) control is the most important treatment in patients with heart failure with preserved reduction. ${ }^{2}{ }^{3}$ Calcium channel blockers (CCBs) are not recommended for routine treatment in patients with heart failure with reduced ejection fraction, ${ }^{2}$ because they might reduce the myocardial contractility. However, their effects on LV diastolic function are still not fully elucidated. A combination of CCB and an angiotensin receptor blocker could improve LV relaxation effectively in hypertensive patients. ${ }^{4}$ On the other hand, dihydropyridine CCBs might have unfavourable effects on diastolic function due to reflex tachycardia. Azelnidipine is a unique dihydropyridine $\mathrm{CCB}$ that lowers $\mathrm{BP}$ as well as amlodipine without increasing heart rate, and even slightly decreasing it. ${ }^{5}$ We previously demonstrated that azelnidipine improved LV relaxation in hypertensive patients with $\mathrm{LV}$ diastolic dysfunction in the prospective multicentre, Clinical impact of Azelnidipine on Left VentricuLar diastolic function and OutComes in patients with hypertension (CALVLOC) trial. $^{6}$

In this post hoc analysis of the CALVLOC study, we investigated: (1) whether there was a difference in LV diastolic function between hypertensive patients with and without diabetes; and (2) whether azelnidipine could improve diastolic function in patients with diabetes as well as in patients without diabetes.

\section{METHODS}

Study design

The CALVLOC trial was a multicentre, prospective single-arm trial to evaluate the effects of azelnidipine treatment on LV relaxation in hypertensive patients. The study design and main results were reported elsewhere. ${ }^{6}$ We enrolled patients with stage 1 or 2 essential hypertension (mean systolic BP $>140 \mathrm{~mm} \mathrm{Hg}$ or diastolic BP $>90 \mathrm{~mm} \mathrm{Hg}$ ) who had impaired LV relaxation, defined as septal mitral annular relaxation velocity $\left(\mathrm{e}^{\prime}\right)<8 \mathrm{~cm} / \mathrm{s}$ on echocardiography, irrespective of history of antihypertensive treatment. The exclusion criteria were $\mathrm{LV}$ ejection fraction of $<50 \%$, atrial fibrillation and the administration of CCBs other than amlodipine. The study patients were enrolled between January 2006 and October 2007 in 11 participating institutes within Osaka, Hyogo, Aichi and Gifu prefectures, Japan.

Azelnidipine $(16 \mathrm{mg} /$ day $)$ was administered to patients who had not received CCBs. If patients had been on amlodipine at the time of enrolment, amlodipine was substituted with $16 \mathrm{mg}$ of azelnidipine. No other medications were changed throughout the study period. Patients were assessed at 4-8-week intervals at least for 24 weeks, and BP and heart rate were measured at each study visit. Blood and urine tests were performed at baseline and at the end of the study, including measurement of fasting blood glucose, glycosylated haemoglobin (HbAlc), brain natriuretic peptide, high sensitivity $\mathrm{C}$ reactive protein and urine albumin.
Echocardiography was recorded before enrolment and at the end of the study. The primary end points were changes in septal $\mathrm{e}^{\prime}$ velocity and the ratio of transmitral $\mathrm{E}$ wave velocity to the $\mathrm{e}^{\prime}\left(\mathrm{E} / \mathrm{e}^{\prime}\right.$ ratio) from the baseline to follow-up. Secondary end points included changes in $\mathrm{BP}$, heart rate, $\mathrm{LV}$ wall thickness, $\mathrm{LV}$ mass index and left atrial volume index on echocardiography. Written informed consent was obtained from each patient enrolled in the study.

The present study was conducted as a post hoc analysis of the CALVLOC trial. We divided the study patients into two groups based on the presence or absence of diabetes, which was diagnosed according to the guidelines of Japan Diabetes Society. ${ }^{7}$ We compared the differences in the primary and secondary end points, described above, between the two groups.

\section{Analysis of echocardiography}

We performed standard echocardiography examination in all patients. Doppler echocardiographic assessment included the peak velocities of transmitral $\mathrm{E}$ and $\mathrm{A}$ wave and deceleration time of the $\mathrm{E}$ wave. We recorded tissue Doppler images from the apical four-chamber view and measured septal $\mathrm{e}^{\prime}$ velocity on the pulse-wave Doppler spectrum. LV mass was calculated as $0.80 \times(1.04 \times[$ [septal wall thickness in diastole+LV end-diastolic dimension+posterior wall thickness in diastole $\}^{3}-\mathrm{LV}$ end-diastolic dimension $\left.^{3}\right]$ ) +0.6 (grams) and indexed to body surface area as LV mass index. Relative wall thickness was calculated as $2 \times$ (posterior wall thickness in diastole) $/ \mathrm{LV}$ end-diastolic dimension. Left atrial volume $(\mathrm{mL})$ was determined by the prolate ellipse method at ventricular end systole, and it was indexed to body surface area as left atrial volume index. All echocardiography data were measured and determined by two independent doctors or sonographers blinded to the patients' clinical data. All parameters were measured once except $\mathrm{E}$ and $\mathrm{e}^{\prime}$ velocities, which were measured as an average of three consecutive cardiac cycles.

\section{Statistics}

All continuous variables were expressed as mean \pm SD and were compared by one-way analysis of variance (ANOVA). Significance of difference was calculated with Tukey's HSD test for factor analysis. Categorical variables were compared with Fisher's exact test. The influence of age and body mass index on $\mathrm{e}^{\prime}$ velocity was adjusted using analysis of covariance (ANCOVA). The correlations between $\mathrm{e}^{\prime}$ and fasting blood glucose or HbAlc were analysed using linear correlation analysis. The changes in BP, heart rate and $\mathrm{e}^{\prime}$ velocity during treatment were compared between patients with and without diabetes using two-way repeated measure ANOVA. The influence of diabetes on the relation between decrease in BP and increase in $\mathrm{e}^{\prime}$ velocity was analysed using ANCOVA. StatView V.5.0 (SAS Institute Inc) was used for statistical analysis. 


\section{RESULTS}

\section{Patients' characteristics}

The original CALVLOC trial enrolled 253 patients; 21 patients were excluded because of failure to follow-up (15 patients) and protocol violation (6 patients). For the present analysis, four more patients were excluded because of insufficient data on diabetic status. Thus, the final study group for the present analysis consisted of 228 patients. Their mean age was $66 \pm 11$ (range 31-95) years old; $120(52.6 \%)$ were men. Diabetes was diagnosed in 53 patients $(23.2 \%)$, all of whom were diagnosed with type 2 diabetes. Patients with diabetes showed higher fasting blood glucose $(139 \pm 37$ vs 99 $\pm 11 \mathrm{mg} / \mathrm{dL}, \mathrm{p}<0.0001)$ and higher HbA1c $(6.9 \pm 0.7$ vs 5.7 $\pm 0.3 \%, \mathrm{p}<0.0001)$ than patients without diabetes. Table 1 demonstrates the baseline characteristics. There were no differences in age, gender, body size, the prevalence of ischaemic heart disease or stroke, and renal function between patients with and without diabetes. No differences were observed in antihypertensive drugs including amlodipine administered before enrolment between the two groups. Statins were more frequently administered $(45.3 \%$ vs $28.0 \%, \mathrm{p}=0.03)$ in patients with diabetes. High-density lipoprotein cholesterol was significantly lower in patients with diabetes $(50 \pm 13$ vs $56 \pm 16 \mathrm{mg} / \mathrm{dL}$, $\mathrm{p}=0.01$ ) while no differences were observed in other lipid profiles.

\section{Effects of azelnidipine on haemodynamics}

Table 2 demonstrated BP and heart rate on enrolment (baseline) and at the end of study. The mean interval between baseline and follow-up study was 8 months (range 6-10 months). Patients with diabetes had lower systolic BP at baseline than patients without diabetes $(155 \pm 17$ vs $161 \pm 16 \mathrm{~mm} \mathrm{Hg}, \mathrm{p}=0.03)$. No differences were observed in diastolic BP and heart rate at baseline between the two groups.

Azelnidipine treatment significantly decreased systolic and diastolic BP and heart rate in patients with and without diabetes. There were no differences in systolic and diastolic BP and in heart rate after azelnidipine treatment between the two groups. Two-way repeated measure ANOVA was conducted to compare changes of parameters between the two groups before and after treatment. The test for the interaction between systolic BP change and diabetes was significant $(\mathrm{F}=4.49, \mathrm{p}=0.04)$, while the interactions between diabetes and diastolic pressure reduction or heart rate change were not significant $(\mathrm{F}=0.53, \mathrm{p}=0.47$ and $\mathrm{F}=0.48, \mathrm{p}=0.49$, respectively). These results indicated that azelnidipine lowered systolic $\mathrm{BP}$, but not diastolic BP or heart rate, more effectively in patients without diabetes than patients with diabetes.

\section{Diabetes and echocardiography parameters}

The echocardiography parameters at baseline and at follow-up study were demonstrated in table 3. There were no significant differences in LV dimensions and ejection fraction at baseline between patients with and without diabetes. Also, there were no differences in wall thickness and LV mass index between the two groups. Patients with diabetes showed lower $\mathrm{e}^{\prime}$ velocity than patients without diabetes $(5.7 \pm 1.5$ vs $6.1 \pm 1.4 \mathrm{~cm} / \mathrm{s}$, $\mathrm{p}=0.04)$. Patients with diabetes still had lower $\mathrm{e}^{\prime}$ velocity after adjustment with age and body mass index $(\mathrm{p}=0.04$ by ANCOVA). Patients with diabetes had significantly lower E/A ratio $(0.72 \pm 0.18$ vs $0.86 \pm 0.24 \mathrm{~cm} / \mathrm{s}, \mathrm{p}=0.0003)$. Left atrial volume index tended to be larger in patients with diabetes $(p=0.07)$, but no difference was observed in $\mathrm{E} / \mathrm{e}^{\prime}$ ratio between the two groups. HbA1c was weakly but significantly correlated with $\mathrm{e}^{\prime}$ velocity at baseline ( $\mathrm{R}=0.21$, $\mathrm{p}=0.002)$, while there was no correlation between fasting blood glucose and $\mathrm{e}^{\prime}$ velocity $(\mathrm{p}=0.37)$.

Azelnidipine treatment significantly increased $\mathrm{e}^{\prime}$ velocity in patients with diabetes $(5.7 \pm 1.5$ to $6.3 \pm 1.5 \mathrm{~cm} / \mathrm{s}$, $\mathrm{p}=0.0003)$ as well as in patients without diabetes $(6.1 \pm 1.4$ to $6.9 \pm 1.4 \mathrm{~cm} / \mathrm{s}, \mathrm{p}<0.0001)$. Two-way repeated measure ANOVA demonstrated that the interaction between change of $\mathrm{e}^{\prime}$ velocity and diabetes was not significant $(\mathrm{F}=0.48, \mathrm{p}=0.48)$, indicating that increase in $\mathrm{e}^{\prime}$ velocity was not influenced by diabetes (figure 1). The difference in $\mathrm{e}^{\prime}$ velocity between the two groups still remained after azelnidipine treatment $(\mathrm{p}=0.006)$. The increase in $\mathrm{e}^{\prime}$ velocity was significantly correlated with decrease in systolic BP during treatment $(\mathrm{R}=0.25, \mathrm{p}=0.0001)$. This relation was not interacted with presence or absence of diabetes $(\mathrm{F}=0.27, \mathrm{p}=0.60$, by ANCOVA). No significant correlation was observed between changes in $\mathrm{e}^{\prime}$ velocity and those in heart rate $(\mathrm{R}=0.13, \mathrm{p}=0.06)$.

The increase in $\mathrm{e}^{\prime}$ velocity was also weakly but significantly correlated with changes in HbAlc $(\mathrm{R}=0.16$, $\mathrm{p}=0.03)$. There were no significant differences in HbA1c during treatment between patients with diabetes (6.9 \pm 0.7 to $6.8 \pm 0.6 \%, \mathrm{p}=0.29)$ and without diabetes $(5.7 \pm 0.3$ to $5.7 \pm 0.3 \%, \mathrm{p}=0.34)$, therefore, the contribution of changes in HbAlc would be very small even if present.

$\mathrm{E} / \mathrm{e}^{\prime}$ was significantly decreased in patients without diabetes $(11.4 \pm 3.4$ to $10.1 \pm 2.9, \mathrm{p}<0.0001)$ but not in patients with diabetes $(11.5 \pm 4.2$ to $10.8 \pm 3.6, \mathrm{p}=0.11)$. Left atrial volume index was decreased only in patients with diabetes $(20.2 \pm 8.9$ to $19.6 \pm 8.3 \mathrm{~mL} / \mathrm{m} 2, \mathrm{p}=0.004)$. $\mathrm{E} / \mathrm{A}$ ratios were increased during treatment in patients with diabetes $(0.72 \pm 0.18$ to $0.86 \pm 0.24, \mathrm{p}=0.02)$ while the change did not reach statistical significance in patients without diabetes $(0.86 \pm 0.24$ to $0.89 \pm 0.23, \mathrm{p}=0.06)$. The difference in $\mathrm{E} / \mathrm{A}$ ratio between the two groups was not observed after treatment $(\mathrm{p}=0.50)$. No significant changes in LV diameters, ejection fraction, wall thickness or LV mass index were observed after azelnidipine treatment in the two groups.

\section{DISCUSSION}

We investigated the relation between diabetes and LV relaxation in 228 hypertensive patients who received azelnidipine treatment. Patients with diabetes had significantly lower $\mathrm{e}^{\prime}$ velocity and lower $\mathrm{E} / \mathrm{A}$ ratio at 
Table 1 Patients' characteristics

\begin{tabular}{|c|c|c|c|}
\hline & Diabetes & Non-diabetes & p Value \\
\hline Number of patients, n (\%) & $53(23.2 \%)$ & $175(76.8 \%)$ & \\
\hline Age, year & $68 \pm 10$ & $65 \pm 12$ & 0.09 \\
\hline Gender, male/female & $31 / 22$ & $89 / 86$ & 0.35 \\
\hline Height, cm & $158.1 \pm 9.5$ & $159.5 \pm 9.7$ & 0.35 \\
\hline Weight, kg & $62.9 \pm 12.8$ & $62.1 \pm 11.3$ & 0.64 \\
\hline Body mass index & $25.0 \pm 3.3$ & $24.3 \pm 3.3$ & 0.20 \\
\hline Dyslipidaemia, n (\%) & $30(56.6)$ & $76(43.4)$ & 0.12 \\
\hline Smoker, n (\%) & $13(24.5)$ & $61(34.9)$ & 0.18 \\
\hline History of myocardial infarction, n (\%) & $2(3.8)$ & $7(4.0)$ & 0.99 \\
\hline Angina pectoris, $\mathrm{n}(\%)$ & 7 (13.2) & $27(15.4)$ & 0.83 \\
\hline Myocardial infarction+angina, n (\%) & $8(15.1)$ & $31(17.7)$ & 0.84 \\
\hline History of stroke, n (\%) & $3(5.7)$ & $10(5.7)$ & 0.99 \\
\hline \multicolumn{4}{|l|}{ Medications } \\
\hline Amlodipine, n (\%) & $14(26.4)$ & $58(33.1)$ & 0.40 \\
\hline Renin-angiotensin-aldosterone system inhibitors, n (\%) & $28(52.8)$ & $78(44.6)$ & 0.35 \\
\hline$\beta$-blockers, $n(\%)$ & $8(15.6)$ & $26(14.7)$ & 0.99 \\
\hline Diuretics, $\mathrm{n}(\%)$ & $4(7.5)$ & $10(5.7)$ & 0.74 \\
\hline Statins, n (\%) & $24(45.3)$ & $49(28.0)$ & 0.03 \\
\hline Fasting blood glucose, mg/dL & $139 \pm 37$ & $99 \pm 11$ & $<0.0001$ \\
\hline $\mathrm{HbA} 1 \mathrm{c}, \%$ & $6.9 \pm 0.7$ & $5.7 \pm 0.3$ & $<0.0001$ \\
\hline Total cholesterol, mg/dL & $198 \pm 35$ & $207 \pm 31$ & 0.08 \\
\hline Low-density lipoprotein cholesterol, mg/dL & $115 \pm 35$ & $120 \pm 30$ & 0.38 \\
\hline High-density lipoprotein cholesterol, mg/dL & $50 \pm 13$ & $56 \pm 16$ & 0.01 \\
\hline Triglyceride, $\mathrm{mg} / \mathrm{dL}$ & $163 \pm 87$ & $158 \pm 109$ & 0.76 \\
\hline Serum creatinine, $\mathrm{mg} / \mathrm{dL}$ & $0.90 \pm 0.48$ & $0.88 \pm 0.63$ & 0.88 \\
\hline Estimated glomerular filtration rate, $\mathrm{mL} / \mathrm{min} / 1.73 \mathrm{~m}^{2}$ & $61.4 \pm 15.5$ & $63.2 \pm 16.3$ & 0.50 \\
\hline Brain natriuretic peptide, $\mathrm{pg} / \mathrm{dL}$ & $33.4 \pm 40.5$ & $39.3 \pm 66.7$ & 0.56 \\
\hline High sensitive $\mathrm{C}$ reactive protein, $\mathrm{mg} / \mathrm{dL}$ & $1.60 \pm 2.60$ & $1.71 \pm 2.48$ & 0.79 \\
\hline
\end{tabular}

baseline than those without it, while no difference was observed in $\mathrm{E} / \mathrm{e}^{\prime}$ ratio. Azelnidipine treatment for a mean of 8 months significantly lowered heart rate, systolic and diastolic BP in patients with and without diabetes, and patients with diabetes showed larger systolic BP reduction than patients without diabetes. Azelnidipine increased $\mathrm{e}^{\prime}$ velocity in both groups similarly and patients with diabetes still had lower $\mathrm{e}^{\prime}$ velocity after treatment. The changes in $\mathrm{e}^{\prime}$ velocity were almost parallel between patients with and without diabetes (figure 1). The increase in $\mathrm{e}^{\prime}$ velocity was correlated with the decrease in systolic BP by azelnidipine, and this correlation was not affected by presence or absence of diabetes. These results demonstrated that $\mathrm{LV}$ relaxation among the hypertensive patients was more impaired in patients with diabetes than in patients without diabetes and that the improvement of $\mathrm{e}^{\prime}$ velocity by azelnidipine was little affected by presence or absence of diabetes. The latter suggested that hypertension and diabetes might impair LV relaxation through different mechanisms, and that the impairment associated with diabetes might not be improved by adequate BP control.

Prior studies had demonstrated that patients with hypertension as well as diabetes had lower LV diastolic function than those with hypertension or diabetes alone. ${ }^{8-10}$ Hypertension and diabetes impaired left atrial performance, which could reflect diastolic function in an additive fashion, ${ }^{11}$ suggesting that diabetes and

Table 2 Haemodynamic parameters

\begin{tabular}{|c|c|c|c|c|c|c|}
\hline & \multicolumn{3}{|l|}{ Baseline } & \multicolumn{3}{|c|}{ Follow-up study } \\
\hline & Diabetes & Non-diabetes & p Value & Diabetes & Non-diabetes & p Value \\
\hline Systolic blood pressure, $\mathrm{mmHg}$ & $155 \pm 17$ & $161 \pm 16$ & 0.03 & $138 \pm 12^{*}$ & $139 \pm 11^{*}$ & 0.86 \\
\hline Diastolic blood pressure, $\mathrm{mmHg}$ & $85 \pm 13$ & $88 \pm 13$ & 0.11 & $77 \pm 10^{\star}$ & $79 \pm 9^{\star}$ & 0.16 \\
\hline Heart rate, bpm & $73 \pm 10$ & $73 \pm 10$ & 0.99 & $69 \pm 10 \dagger$ & $69 \pm 9^{*}$ & 0.58 \\
\hline
\end{tabular}

Each value depicts mean \pm SD.

${ }^{*} p<0.0001 ; \uparrow p<0.001$ versus baseline. 
Table 3 Echocardiography parameters

\begin{tabular}{|c|c|c|c|c|c|c|}
\hline & \multicolumn{3}{|c|}{ Baseline study } & \multicolumn{3}{|c|}{ Follow-up study } \\
\hline & Diabetes & Non-diabetes & p Value & Diabetes & Non-diabetes & p Value \\
\hline LV end-diastolic dimension, $\mathrm{cm}$ & $4.7 \pm 0.5$ & $4.7 \pm 0.5$ & 0.55 & $4.6 \pm 0.5$ & $4.6 \pm 0.4$ & 0.98 \\
\hline LV end-systolic dimension, cm & $2.9 \pm 0.5$ & $2.8 \pm 0.4$ & 0.12 & $2.9 \pm 0.5 \S$ & $2.8 \pm 0.4$ & 0.11 \\
\hline LV ejection fraction, \% & $68 \pm 7$ & $69 \pm 8$ & 0.10 & $69 \pm 9$ & $70 \pm 7$ & 0.37 \\
\hline Septal wall thickness, cm & $1.0 \pm 0.2$ & $1.0 \pm 0.2$ & 0.14 & $1.0 \pm 0.2$ & $1.0 \pm 0.2$ & 0.14 \\
\hline Posterior wall thickness, cm & $1.0 \pm 0.2$ & $1.0 \pm 0.2$ & 0.64 & $1.0 \pm 0.2$ & $1.0 \pm 0.1$ & 0.09 \\
\hline Relative wall thickness & $0.43 \pm 0.09$ & $0.43 \pm 0.08$ & 0.98 & $0.44 \pm 0.08$ & $0.42 \pm 0.08$ & 0.20 \\
\hline LV mass index, $\mathrm{g} / \mathrm{m}^{2}$ & $99.9 \pm 42.3$ & $92.5 \pm 36.1$ & 0.21 & $91.3 \pm 40.8 \S$ & $90.4 \pm 37.2$ & 0.88 \\
\hline Left atrial volume index, $\mathrm{mL} / \mathrm{m}^{2}$ & $22.9 \pm 9.4$ & $20.2 \pm 8.9$ & 0.07 & $22.6 \pm 8.2$ & $19.6 \pm 8.3 \ddagger$ & 0.02 \\
\hline Peak E velocity, cm/s & $60.8 \pm 14.1$ & $66.8 \pm 15.4$ & 0.01 & $64.8 \pm 16.0$ & $67.4 \pm 15.9$ & 0.31 \\
\hline Peak A velocity, $\mathrm{cm} / \mathrm{s}$ & $84.4 \pm 15.0$ & $81.4 \pm 17.0$ & 0.25 & $84.4 \pm 15.0$ & $81.4 \pm 17.0 \dagger$ & 0.25 \\
\hline$E / A$ & $0.72 \pm 0.18$ & $0.86 \pm 0.24$ & 0.0003 & $0.86 \pm 0.42 \S$ & $0.89 \pm 0.23$ & 0.50 \\
\hline Deceleration time of $\mathrm{E}$ wave, $\mathrm{ms}$ & $234 \pm 57$ & $230 \pm 56$ & 0.68 & $218 \pm 50 \S$ & $222 \pm 46$ & 0.64 \\
\hline $\mathrm{e}^{\prime}, \mathrm{cm} / \mathrm{s}$ & $5.7 \pm 1.5$ & $6.1 \pm 1.4$ & 0.04 & $6.3 \pm 1.5 \dagger$ & $6.9 \pm 1.4^{*}$ & 0.006 \\
\hline$E / e^{\prime}$ & $11.5 \pm 4.2$ & $11.4 \pm 3.4$ & 0.78 & $10.8 \pm 3.6$ & $10.1 \pm 2.9^{*}$ & 0.19 \\
\hline
\end{tabular}

hypertension would impair LV diastolic function through different mechanisms. Hypertension is associated with increased collagen deposition, increased interstitial fibrosis and disturbance of calcium homoeostasis in the myocardium, ${ }^{12}$ all of which may contribute to deteriorating diastolic function. Diabetes may increase LV mass independently of arterial BP. ${ }^{13}$ Collagen deposition around intramural vessels and between myofibres is increased, and collagen type III is accumulated in patients with diabetes, which could mechanically impair

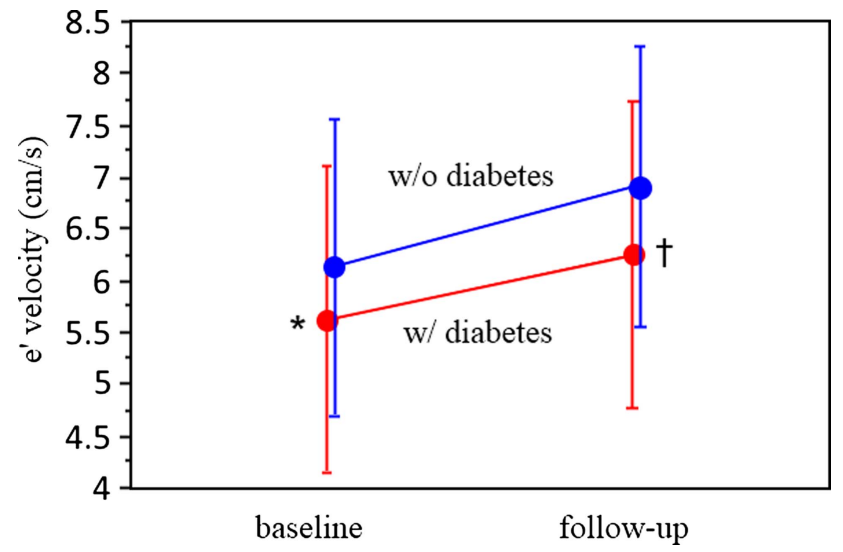

Figure 1 Changes in $\mathrm{e}^{\prime}$ velocity during azelnidipine treatment. Patients with diabetes showed lower $\mathrm{e}^{\prime}$ velocity than patients without diabetes ( $5.7 \pm 1.5$ vs $6.1 \pm 1.4 \mathrm{~cm} / \mathrm{s}, \mathrm{p}=0.04)$.

Azelnidipine treatment significantly increased $e^{\prime}$ velocity in patients with diabetes $(p=0.0003)$ as well as in patients without diabetes $(p<0.0001)$. The changes in $e^{\prime}$ velocity were parallel between the two groups, implying that the effects of azelnidipine were similar between them. Patients with diabetes had lower $e^{\prime}$ velocity than patients without diabetes even after treatment $(6.3 \pm 1.5$ vs $6.9 \pm 1.4 \mathrm{~cm} / \mathrm{s}, \mathrm{p}=0.006)$. ${ }^{*} \mathrm{p}=0.04$, $\mathrm{tp}=0.006$ versus patients without diabetes. diastolic function. ${ }^{14}$ It is unclear how the changes associated with diabetes and those with hypertension are overlapped or interacted in the development of diastolic dysfunction.

The present study was a relatively small one and not conducted as a prespecified subgroup analysis and, therefore, the results were not fully conclusive. Improvement of diastolic function in hypertensive patients is correlated with the degree of systolic BP reduction regardless of antihypertensive agents. ${ }^{4}$ However, it is unclear whether the changes in $\mathrm{e}^{\prime}$ velocity were caused by BP lowering or by a unique action of azelnidipine. The follow-up period might not be long enough to detect the clinical outcomes. ${ }^{15}$ We did not determine the variability of $\mathrm{e}^{\prime}$ velocity measurement among the institutions, although $\mathrm{e}^{\prime}$ velocity could be a relatively robust parameter. We measured only septal $\mathrm{e}^{\prime}$ velocity for the original CALVLOC study. ${ }^{14}$ Although septal $\mathrm{e}^{\prime}$ velocity might be sufficient for the evaluation of $\mathrm{LV}$ relaxation in most cases, wall motion abnormality within the septum might affect the septal velocity. We did not assess myocardial ischaemia directly, and subclinical coronary artery disease might be dismissed. We did not analyse the duration of diabetes and the effects of antidiabetic treatment or those of antihypertensive drugs concomitantly used.

Despite the limitations described above, the present study provided an important insight into the mechanisms of LV diastolic dysfunction in hypertension and diabetes. Standard BP lowering might not be enough for improvement of diastolic function in hypertensive patients with diabetes. It is unclear whether diabetic control has an additive or synergic effect with BP lowering on diastolic function. The correlation between HbA1c and $\mathrm{e}^{\prime}$ velocity in the present study was very weak. Intensive glycaemic control might not be as effective as BP lowering for LV diastolic dysfunction, as suggested in the large-scale trials. ${ }^{16-18}$ 
Author affiliations

${ }^{1}$ Department of Cardiology, Sakurabashi Watanabe Hospital, Osaka, Japan

${ }^{2}$ Department of Cardiovascular Medicine, Okayama University, Graduate School of Medicine, Okayama, Japan

${ }^{3}$ Division of Cardiology, Kansai Electric Power Hospital, Osaka, Japan

${ }^{4}$ Division of Medicine, Ibaraki Iseikai Hospital, Ibaraki, Japan

${ }^{5}$ Department of Internal Medicine, Iwasa Dai-ichi Hospital, Gifu, Japan

${ }^{6}$ Department of Cardiology, Higashi-Takarazuka Satoh Hospital, Takarazuka, Japan

Collaborators CALVLOC trial investigators: Atsuhito Otuska, MD (Ibaraki Iseikai Hospital, Ibaraki, Japan); Kou Fujisawa, MD (Iwasa Dai-ichi Hospital, Gifu, Japan); Yorihiko Higashino, MD (Higashi-Takarazuka Sato Hospital, Takarazuka, Japan); Kei Tawarahara, MD (Hamamatsu Red-Cross Hospital, Hamamatsu, Japan); Mikio Mukai, MD (Kinki Chuo Hospital, Itami, Japan); Masanori Shinoda, MD (Kouseiren Kamo General Hospital, Toyota, Japan); Taro Minagawa, MD (Minagawa Clinic, Gifu, Japan); and Naoki Goto, MD (Goto Clinic, Gifu, Japan).

Contributors KI provided the study design of the present subanalysis along with $\mathrm{HI}$, performed statistical analysis, interpreted the results and wrote the draft of the manuscript. $\mathrm{HI}$ provided the concept and study design of original CALVLOC study and its subanalysis, review of data and revision of the manuscript. KI, MD, FN, TN and ST assisted in analysis and interpretation of original CALVLOC data. All authors carefully read and approved the manuscript.

Funding The original CALVLOC trial was supported by Japan Vascular Disease Research Foundation.

Competing interests None.

Ethics approval The CALVLOC trial was conducted in accordance with the Declaration of Helsinki and with the approval of the institutional ethics committees in each participating institution.

Provenance and peer review Not commissioned; externally peer reviewed.

Data sharing statement Extra data can be accessed via the Dryad data repository at http://datadryad.org/ with the doi:10.5061/dryad.h23d1.

Open Access This is an Open Access article distributed in accordance with the Creative Commons Attribution Non Commercial (CC BY-NC 4.0) license, which permits others to distribute, remix, adapt, build upon this work noncommercially, and license their derivative works on different terms, provided the original work is properly cited and the use is non-commercial. See: http:// creativecommons.org/licenses/by-nc/4.0/

\section{REFERENCES}

1. Mogelvang R, Sogaard P, Pedersen S, et al. Tissue Doppler echocardiography in persons with hypertension, diabetes, or ischaemic heart disease: the Copenhagen City Heart Study. Eur Heart J 2009;30:731-9.
2. Yancy C, Jessup M, Bozkurt B, et al. 2013 ACCF/AHA guideline for the management of heart failure: a report of the American College of Cardiology Foundation/American Heart Association Task Force on Practice Guidelines. J Am Coll Cardiol 2013;62:e147-239.

3. McMurray J, Adamopoulos S, Anker S, et al. ESC guidelines for the diagnosis and treatment of acute and chronic heart failure 2012: the Task Force for the Diagnosis and Treatment of Acute and Chronic Heart Failure 2012 of the European Society of Cardiology. Developed in collaboration with the Heart Failure Association (HFA) of the ESC. Eur Heart J 2012;33:1787-847.

4. Solomon S, Verma A, Desai A, et al. Effect of intensive versus standard blood pressure lowering on diastolic function in patients with uncontrolled hypertension and diastolic dysfunction. Hypertension 2010;55:241-8.

5. Yamagishi T. Efficacy of azelnidipine on home blood pressure and pulse rate in patients with essential hypertension: comparison with amlodipine. Hypertens Res 2006;29:767-73.

6. Ito $\mathrm{H}$, Ishii $\mathrm{K}$, Iwakura $\mathrm{K}$, et al. Impact of azelnidipine treatment on left ventricular diastolic performance in patients with hypertension and mild diastolic dysfunction: multi-center study with echocardiography. Hypertens Res 2009;32:895-900.

7. Kuzuya T, Nakagawa S, Satoh J, et al. Report of the Committee on the classification and diagnostic criteria of diabetes mellitus. Diabetes Res Clin Pract 2002;55:65-85.

8. Liu J, Palmieri V, Roman M, et al. The impact of diabetes on left ventricular filling pattern in normotensive and hypertensive adults: the Strong Heart Study. J Am Coll Cardiol 2001;37:1943-9.

9. Wachter R, Lüers C, Kleta S, et al. Impact of diabetes on left ventricular diastolic function in patients with arterial hypertension. Eur J Heart Fail 2007;9:469-76.

10. Russo C, Jin Z, Homma S, et al. Effect of diabetes and hypertension on left ventricular diastolic function in a high-risk population without evidence of heart disease. Eur J Heart Fail 2010;12:454-61.

11. Mondillo S, Cameli M, Caputo M, et al. Early detection of left atrial strain abnormalities by speckle-tracking in hypertensive and diabetic patients with normal left atrial size. J Am Soc Echocardiogr 2011;24:898-908

12. Ouzounian M, Lee D, Liu P. Diastolic heart failure: mechanisms and controversies. Nat Clin Pract Cardiovasc Med 2008;5:375-86.

13. Aneja A, Tang W, Bansilal S, et al. Diabetic cardiomyopathy: insights into pathogenesis, diagnostic challenges, and therapeutic options. Am J Med 2008;121:748-57.

14. Boudina S, Abel E. Diabetic cardiomyopathy, causes and effects. Rev Endocr Metab Disord 2010;11:31-9.

15. Cioffi G, Faggiano P, Lucci D, et al. Left ventricular dysfunction and outcome at two-year follow-up in patients with type 2 diabetes: the DYDA study. Diabetes Res Clin Pract 2013;101:236-42.

16. Action $\mathrm{T}$, Gerstein $\mathrm{H}$, Miller $\mathrm{M}$, et al. Effects of intensive glucose lowering in type 2 diabetes. $N$ Engl J Med 2008;358:2545-59.

17. Patel A, MacMahon S, Chalmers J, et al. ADVANCE C. Intensive blood glucose control and vascular outcomes in patients with type 2 diabetes. N Engl J Med 2008;358:2560-72.

18. Duckworth W, Abraira C, Moritz T, et al. Glucose control and vascular complications in veterans with type 2 diabetes. $N$ Engl $J$ Med 2009;360:129-39. 